\title{
Willingness among obese pregnant women to accept MRI scan
}

Geiker, Nina Rica Wium; Thomsen, H; Astrup, Arne

Published in:

Maternal and Pediatric Nutrition

DOI:

$10.4172 / 2472-1182.1000106$

Publication date:

2016

Document version

Publisher's PDF, also known as Version of record

Document license:

CC BY

Citation for published version (APA):

Geiker, N. R. W., Thomsen, H., \& Astrup, A. (2016). Willingness among obese pregnant women to accept MRI scan. Maternal and Pediatric Nutrition, 2(1), [1000106]. https://doi.org/10.4172/2472-1182.1000106 


\title{
Willingness among Obese Pregnant Women to Accept MRI Scan
}

\section{Wium Geiker NR ${ }^{1 *}$, Thomsen $\mathrm{H}^{2}$ and Astrup $\mathrm{A}^{1,3}$}

${ }^{1}$ Clinical Nutrition Research Unit, Copenhagen University Hospital Herlev and Gentofte, Denmark

${ }^{2}$ Department of Diagnostic Radiology, Copenhagen University Hospital Herlev and Gentofte, Denmark

${ }^{3}$ Department of Nutrition, Exercise and Sports, University of Copenhagen, Denmark

\begin{abstract}
Background/Aim: Magnetic resonance imaging (MRI) is considered safe to perform during pregnancy. In spite of this many women are reluctant to undergo the examination. Weight gain is to be expected during pregnancy, but little is known about changes in the compartmentalization of abdominal fat. We therefore undertook a study of the willingness of obese women to undergo MRI during pregnancy.

Method: Obese pregnant women, body mass index (BMI) $30-45 \mathrm{~kg} / \mathrm{m}^{2}$, participating in a weight management intervention study, were offered three MRI scans to be performed during pregnancy. One hundred and one women were offered MRI scanning in gestational week (GW) 15, 64 in GW 32, and 45 in GW 40.

Results: Of 106 women offered MRI scans 102 completed (96\%) at least one scan. In total 177 out of 210 possible scans were completed. The proportion of women who completed first, second and third MRI scans were $96 \%, 83 \%$ and $61 \%$ respectively. Primary cause for incomplete MRI scans were no-show (45\%); no reported concern for safety as a cause.

Conclusion: A majority of the women accepted MRI scans in GW 15, 32 and 40. Thorough, information about the safety of the method, and the applicability of the results, encouraged participation.
\end{abstract}

Keywords: Magnetic resonance imaging; Diagnostic radiology; Gestational weight gain; Pregnancy; Obesity

Abbreviations: BMI: Body Mass Index; GWG: Gestational Weight Gain; GW: Gestational Week; MRI: Magnetic Resonance Imaging

\section{Introduction}

Overweight and obese pregnant women are at increased risk of developing serious complications related to pregnancy and childbirth due to their excessive weight and gestational weight gain (GWG) [13]. More than $60 \%$ pregnant with BMI above $30 \mathrm{~kg} / \mathrm{m}^{2}$ exceed the BMI specific Institute of Medicine guidelines for GWG, thereby being at increased risk of developing gestational diabetes, hypertension, preeclampsia and preterm birth [4-6]. Apart from excessive GWG posing a risk during pregnancy, suboptimal maternal dietary intake is associated with fetal adiposity and abdominal fat distribution, maternal weight retention after birth, and the offspring being large for gestational age [1,7-9].

Weight gain is required during pregnancy, but little is known about concomitant change in maternal abdominal fat compartments and accompanying changes in metabolism. Magnetic resonance imaging measures body composition accurately, and it is safe to perform during pregnancy $[10,11]$. Many women might refuse to undergo a MRI scan during pregnancy due to concerns about impact on the fetus, so we investigated the willingness of pregnant women enrolled in a dietary intervention trial to undergo MRI.

\section{Material and Methods}

Obese pregnant women, BMI $30-45 \mathrm{~kg} / \mathrm{m}^{2}$, enrolled into the weight management intervention study approach, were offered three MRI scans to be performed in gestational week (GW) 15,32 and 40 . We registered the cause of any canceled or failed scans when possible.

All women received written and oral information before giving consent. The study was approved by Ethical Committee for the Regional Capital of Copenhagen H-3-2013-119, and registered at Clinical trials as NCT01894139.

\section{MRI Scan}

All the women were given oral and written information of the MRI scans prior to inclusion in the study. They were informed that the MRI apparatus is an open machine using magnetic and radio waves, and that it does not emit X-rays or any other type of radiation. They were told that the large magnet causes a banging noise while the scanner is in operation, and that they will be provided with hearing protection. All current evidence indicates that measurements can be repeated without any danger to either woman or foetus, and the women were assured that the MRI scans were completely voluntary. The women were also informed of the specific purpose of MRI; that is to measure the change in subcutaneous and visceral adipose tissue, liver and muscle fat, during pregnancy, and that MRI measures these parameters precisely and reliably.

All MRI scans were performed at Copenhagen University Hospital Herlev, Department of Diagnostic Radiology, on Thursdays between the hours of 3 and 8 p.m. The measurements were performed to investigate the change in subcutaneous, visceral, liver, and muscle fat, during pregnancy. MRI measurements were performed using an open Panorama 1.0T system (Phillips, Besr Netherlands) with a Sense Body XLarge coil (Figure 1). Each MRI examination took 30 minutes.

*Corresponding author: Wium Geiker NR, Clinical Nutrition Research Unit, Copenhagen University Hospital Herlev and Gentofte, Denmark, Tel: 4538674194; E-mail: nina.rica.wium.geiker@regionh.dk

Received January 05, 2016; Accepted January 28, 2016; Published February 07, 2016

Citation: Geiker NRW, Thomsen H, Astrup A (2016) Willingness among Obese Pregnant Women to Accept MRI Scan. Matern Pediatr Nutr 2: 106. doi:10.4172/ mpn.1000106

Copyright: () 2016 Geiker NRW, et al. This is an open-access article distributed under the terms of the Creative Commons Attribution License, which permits unrestricted use, distribution, and reproduction in any medium, provided the original author and source are credited. 


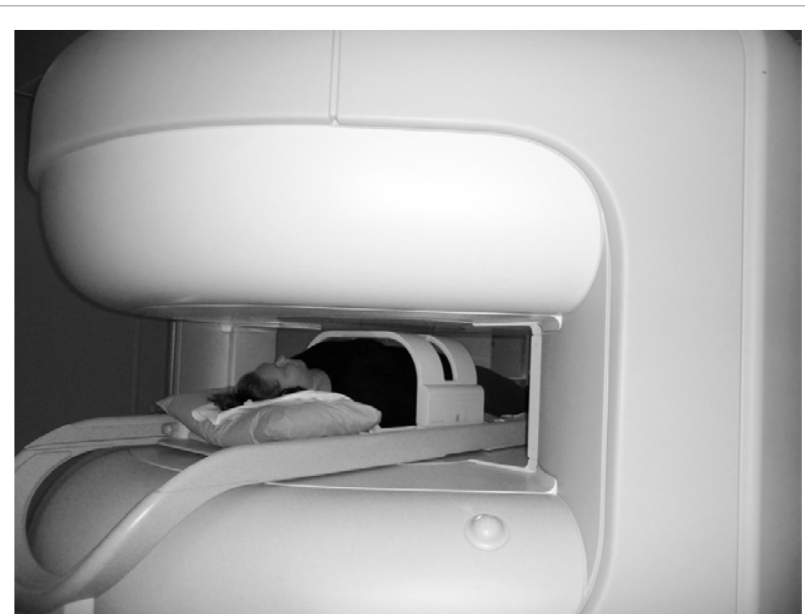

Figure 1: Panaroma 1T MRI-Unit. The patients lay on their backs for the first scan, and had possibility of lying on their side, stabilized with cushions, later in pregnancy.

The picture is used with permission given from subject.

\section{Statistics}

The results were two simple categorical variables 90 so data were registered in Excel (Microsoft) and statistical calculations were performed in this program. Data are shown as true values and percentages.

\section{Results}

The women were all pregnant and weighed $96.8 \pm 11.7 \mathrm{~kg}$ at inclusion with BMI $34.3 \pm 3.6 \mathrm{~kg} / \mathrm{m}^{2}$. Of the 106 women offered MRI scans 102 completed $(96 \%)$ at least one of three possible scans. A total of 177 out of $210(82 \%)$ possible scans were completed (Table 1). In GW 15 and 32 more than $80 \%$ of possible MRI scans were completed. Causes for not completing are presented in Table 2; none were due to safety concerns. In GW 40 cancelations and no-shows were due to birth, or the woman being too large to fit into the scanner.

\section{Discussion}

The majority of the obese pregnant women accepted to have MRI scans performed during their pregnancy, and felt safe once given the information about the procedure. We know of no previous studies of the willingness of pregnant women to undergo MRI scans, and of only a few studies in non-pregnant individuals [12-14]. Though some of the subjects in these studies were ill, fewer accepted MRI (between 60 and 70\%) than in the present study [12-14].

Various reasons may influence the willingness to accept MRI scans during pregnancy. One is that MRI is typically used to image malignant growth or broken bones MRI is therefore coupled to being ill and in pain. In itself an MRI scan causes no physical pain and it is a noninvasive test. Despite this Smith et al. found a lower willingness to undergo MRI than to undergo invasive testing, such as skin biopsy, among patients with advanced malignancies [13], even though improved diagnosis of a disease would be thought to be motivational for these patients.

In the initial screening process of the present study we experienced a certain proportion of eligible women were reluctant to undergo MRI. The anxiety was not specifically towards MRI scan but to the uncertainty of the procedure. Once subjects were informed of the method, safety and applicability of the results none declined to undergo MRI stating

\begin{tabular}{|c|c|c|}
\hline GW & Eligible, $\mathbf{N}$ & MRI performed (\%) \\
\hline 15 & 101 & 96 \\
\hline 32 & 64 & 83 \\
\hline 40 & 45 & 61 \\
\hline Note: GW: gestational week, MR: magnetic resonance imaging \\
\hline
\end{tabular}

Table 1: Proportion of completed MRI scans.

\begin{tabular}{|l|c|c|}
\hline Cause & N & Percentage (\%) \\
\hline No-show & 15 & 45 \\
\hline Cancellation without given cause & 9 & 27 \\
\hline Claustrophobia & 4 & 12 \\
\hline III at scheduled appointment & 2 & 6 \\
\hline Too tight in scanner & 2 & 6 \\
\hline Declining with no given cause & 1 & 3 \\
\hline
\end{tabular}

Note: MRI: Magnetic resonance imaging

Table 2: Causes for non-completed MRI scans.

safety as a cause.

Similarly to Smith et al., we found that supplying detailed information about the MRI procedure increased willingness [13]. The methods to be applied in the present investigation, including MRI, were described at information meetings with women potentially to be enrolled in the study. We found that some individuals expressed anxiety about MRI, but this diminished when they learned that it is a safe procedure. They were informed that even though MRI is not as commonly used during pregnancy as ultra sound it gives a clear and true image. In some settings fetal MRI is used for prenatal diagnosis and it can show anatomical structures as well as brain development $[10,11,15,16]$.

Performing MRI in obese pregnant women can be difficult due to their large and increasing waist circumference. In the present study two of the planned MRI scans (one in GW 32 and one in GW 40) were not completed due to the woman being too large to fit into the scanner. This was also experienced by Anblagan et al. when performing MRI scans in GW 35 to study fetal fat [17]. In the present study we planned the third MRI to be performed from time of childbirth and up to three weeks later. In some cases the MRI was not performed due to the women giving birth, or being too exhausted to participate in the immediate postpartum period.

Women in the present study were all included in a large dietary intervention trial, APPROACH. In this study we investigate the effect of optimizing GWG and nutrition during pregnancy on weight and body composition and fat compartments. The MRI scan is the only method that safely and with high accuracy can identify the different compartments of body fat. The high rate of willingness to undergo MRI during pregnancy in the present study is encouraging. The MRI data, together with knowing the subjects' dietary intake, made it possible to investigate changes during pregnancy in relation to diet, abdominal fat distribution and fetal growth.

In conclusion, of 106 obese pregnant women 96\% (102) completed at least one MRI scan. Safety of MRI scans was not stated as a concern or a reason for not completing MRI. The reasons for declining were multiple, with no-show and cancellation without given cause being the most common. Thorough information about the method and the applicability of the results encouraged participation.

\section{Acknowledgements}

Above all we would like to thank the women for their participation in the study. 
Citation: Geiker NRW, Thomsen H, Astrup A (2016) Willingness among Obese Pregnant Women to Accept MRI Scan. Matern Pediatr Nutr 2: 106. doi:10.4172/mpn.1000106

Page 3 of 3

We thank MRI physicist Elizaveta Chabanova for coordination of MRI scans and collection of raw data.

\section{Funding}

APPROACH is funded by Danish Dairy Foundation, Danish Agriculture and Food Council, Danish Pig Meat Industries, Nordea Foundation, LEGO Charity, PharmaNord and PharmoVital. None of the funders have any influence on design, execution, or data handling of the investigation, or on interpretation and dissemination of the

\section{References}

1. Thangaratinam S, Rogozińska E, Jolly K, Glinkowski S, Roseboom T, et al. (2012) Effects of interventions in pregnancy on maternal weight and obstetric outcomes: Meta-analysis of randomised evidence. BMJ 16: 344

2. Vinter CA, Tanvig MH, Damm P, Naver KV, Andreasen KR, et al. (2012) Overvægtige gravide og komplikationer i relation til graviditet og fødsel. Ugeskr Laeger 174: 1079-1082.

3. Vinter CA, Jensen DM, Ovesen P, Beck-Nielsen H, Jørgensen JS (2011) The LiP (Lifestyle in Pregnancy) Study A randomized controlled trial of lifestyle intervention in 360 obese pregnant women. Diabetes care 34: 2502-2507.

4. Yaktine AL, Rasmussen KM (2009) Weight Gain During Pregnancy: Reexamining the Guidelines. National Academies Press.

5. Nohr EA, Bech BH, Vaeth M, Rasmussen KM, Henriksen TB, et al. (2007) Obesity, gestational weight gain and preterm birth: a study within the Danish National Birth Cohort. Paediatr Perinat Epidemiol 21: 5-14.

6. Nohr EA, Vaeth M, Baker JL, Sørensen TI, Olsen J, et al. (2008) Combined associations of prepregnancy body mass index and gestational weight gain with the outcome of pregnancy. Am J Clin Nutr 87: 1750-1759.

7. Blumfield ML, Hure AJ, MacDonald-Wicks LK, Smith R, Simpson SJ, et al. (2012) Dietary balance during pregnancy is associated with fetal adiposity and fat distribution. Am J Clin Nutr 96: 1032-1041.
8. Moses RG, Luebke M, Petocz P, Brand-Miller JC (2007) Maternal diet and infant size 2 y after the completion of a study of a low-glycemic-index diet in pregnancy. Am J Clin Nutr 86: 1806.

9. Knudsen VK, Heitmann BL, Halldorsson TI, Sørensen TI, Olsen SF (2013) Maternal dietary glycaemic load during pregnancy and gestational weight gain, birth weight and postpartum weight retention: a study within the Danish National Birth Cohort. B J Nutr 109: 1471-1478.

10. Brandt K, Hattery R (1997) MRI during pregnancy. European radiology 7: 821.

11. Gilk T, Kanal E (2013) Interrelating sentinel event alert\# 38 with the ACR guidance document on MR safe practices: 2013. An MRI accreditation safety review tool. J Magn Reson Imaging 37: 531-543.

12. Kuller LH, Margolis KL, Gaussoin SA, Bryan NR, Kerwin D, et al. (2010) Relationship of hypertension, blood pressure, and blood pressure control with white matter abnormalities in the Women's Health Initiative Memory Study (WHIMS)-MRI trial. J Clin Hypertens 12: 203-212.

13. Smith J, Benjamin M, Yim J, James R, Ramanathan R, et al. (2009) Prospective evaluation of patient perceptions and willingness to undergo pharmacodynamic and pharmacokinetic tests in early phase oncology trials. J Clin Oncol 27: 15s.

14. Jaramillo SA, Felton D, Andrews L, Desiderio L, Hallarn RK, et al. (2007) Enrollment in a brain magnetic resonance study: results from the Women's Health Initiative Memory Study Magnetic Resonance Imaging Study (WHIMSMRI). Acad radiol 14: 603-612.

15. Prayer D (2011) Fetal MRI. Top Magn Reson Imaging 22: 89.

16. Prayer D, Brugger PC, Prayer L (2004) Fetal MRI: techniques and protocols Pediatr Radiol 34: 685-693.

17. Anblagan D, Deshpande R, Jones N, Costigan C, Bugg G, et al. (2013) Measurement of fetal fat in utero in normal and diabetic pregnancies using magnetic resonance imaging. Ultrasound Obstet Gynecol 42: 335-340.
Citation: Geiker NRW, Thomsen H, Astrup A (2016) Willingness among Obese Pregnant Women to Accept MRI Scan. Matern Pediatr Nutr 2: 106. doi:10.4172/ mpn.1000106

\section{OMICS International: Publication Benefits \& Features}

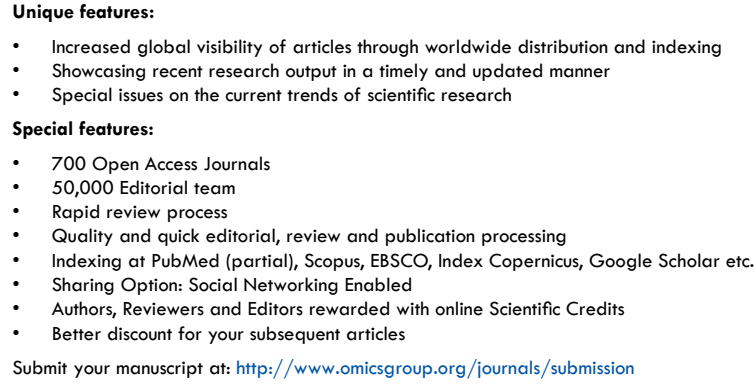

